\title{
A New Clustering Methodology for the Analysis of Sorted or Categorized Stimuli
}

\author{
WAYNE S. DESARBO \\ School of Business Administration, The University of Michigan, Ann Arbor, MI 48109-1234 \\ KAMEL JEDIDI \\ Columbia University \\ MICHAEL D. JOHNSON \\ University of Michigan
}

Key words: Cluster Analysis, Categorization, Sorting Tasks, Maximum Likelihood Estimation

\begin{abstract}
This paper introduces a new stochastic clustering methodology devised for the analysis of categorized or sorted data. The methodology reveals consumers' common category knowledge as well as individual differences in using this knowledge for classifying brands in a designated product class. A small study involving the categorization of 28 brands of U.S. automobiles is presented where the results of the proposed methodology are compared with those obtained from KMEANS clustering. Finally, directions for future rescarch are discussed.
\end{abstract}

A wide range of methods and procedures exists for the analysis of similarity relations among stimuli. These methods range from traditional spatial multidimensional scaling methods (Shepard 1962; Kruskal 1964) to network clustering methods (Johnson 1967; Shepard and Arabie 1979). The input to such procedures is typically some measure of similarity, whether obtained from paired comparison judgments, or derived from some similarity-based response (e.g., sorting data, classification errors, preference relations, or choice data). One such class of input proximity data is the sorting of stimuli (on the basis of their similarity) into homogeneous subsets or categories. Sorting tasks are employed in a wide range of basic and applicd rescarch contexts. When subjects face a large number of stimuli (Rao and Katz 1971) or have a limited ability to respond (Horton and Markman 1980 ), a sorting task may be gainfully employed.

Unfortunately, traditional methods may be ill-suited to this particular type of similarity-based response. Such methods may not capture the category perceptions that underlie the sorting task or the individual differences involved. Our goal is to describe a new clustering methodology designed specifically for the analysis

*Wayne S. DeSarbo is the S. S. Kresge Distinguished Professor of Marketing and Statistics, and Michael D. Johnson is Associatc Professor of Marketing, both at the University of Michigan's School of Business Administration. Kamel Jedidi is Assistant Professor of Marketing at Columbia University's Graduate School of Business. The authors gratefully acknowledge DuPont Incorporated for providing financial support for this research. 
of categorized or sorted stimuli. The methodology describes consumers' common category knowledge, the graded structure of these common categories, and individual differences in the use of the categories in a sorting task. We first describe sorting tasks, how they reveal category perceptions, and the proposed methodology. An illustration of the methodology is then presented with respect to a sort of 28 major U.S. automobile nameplates.

\section{Sorting tasks and category knowledge}

Sorting tasks provide researchers with a valuable alternative to traditional pairedcomparison similarity judgments. They are particularly well-suited to studies involving large stimulus sets where exhaustive paired comparison judgments are infeasible (Rao and Katz 1971). Asking subjects to provide excessive paired comparisons may result in fatigue and alter the basis of their judgments (Johnson, Lehmann, and Horne 1990). Having subjects sort the stimuli into piles of similar alternatives greatly simplifies the subjects' task.

Importantly, a sorting task should reveal consumers' product category knowledge. These product categories vary from relatively abstract, superordinate categories (e.g., modes of transportation), to intermediate level categories (e.g., sporty automobiles), to more concrete, subordinate level groupings (e.g., expensive Japanese sports cars). Rosch (1975) and Mervis and Rosch (1981) define a category as a group of items that are treated or labeled as equal even though they may be discriminated on the basis of their attributes. Likewise, a consumer who classifies brands into the same pile perceives these brands as relatively equal with respect to some criteria.

Individuals may differ in their perception and use of subordinate level distinctions. At the same time, perceptions should be more consistent across individuals at more intermediate or basic levels of categorization (Rosch 1977). Put differently, there are levels of category knowledge that are relatively universal for a given culture and are typically the first perceptual distinctions made in a sorting task. For example, although consumers may perceive quite different subcategories of sporty cars they should be more consistent in their perception of sporty versus luxury cars. When administered across subjects, a sorting task should reveal this common category knowledge.

Meanwhile, differences from subject to subject should help reveal the structure of these commonly held categories. Category membership is naturally graded. Some category members are relatively prototypical or good examples of a category (Rosch 1975; Medin and Smith 1984). Other members are more atypical of a category and thus may be poor examples of multiple categories. For example, an Escort GT may be both an economy car and a sporty car though not prototypical of either. A sorting task should reveal this graded, overlapping category structure in that prototypical members should be more consistently sorted together across consumers than are more atypical members. 
Individuals also differ in their propensity to use common product categories (e.g., sporty versus luxury cars) as a basis for sorting stimuli. A consumer who is more familiar with sports cars may sort these cars into several personally relevant subcategories (e.g., expensive Japanese versus inexpensive Japanese sports cars) while lumping somewhat unfamiliar luxury cars into a single pile. Similarly, a consumer who is more familiar with luxury cars may form several luxury subcategories while lumping somewhat unfamiliar sports cars into a single pile. As a result, the weights placed on common categories in the final stimulus sorts may vary from consumer to consumer.

\section{A new clustering methodology for sorted or categorized stimuli}

A number of categorization studies in psychology and marketing utilize a sorting task procedure. Basically, the entire set of stimulus objects is placed on cards, one object per card. The subject is then asked to sort the cards into as many or few piles as he/she desires, congruent with the similarities and dissimilarities perceived among the stimuli. The subject is asked to place the cards (stimuli) that they view as similar in the same pile. Given such a data collection procedure, we are proposing a new methodology designed specifically to examine perceptual categorization. The data collected is "subject conditional" in the sense that subjects may utilize differing numbers of piles/groups, as well as differing numbers and types of objects per pile/group. The clustering methodology derives common category perceptions, the graded structure of the categories, and individual differences in the use of these perceptions in a sorting task.

\subsection{The model}

We ask consumers to subjectively group a designated set of brands into piles on whatever basis they desire, where the number of piles is determined by the individual consumer. Let:

$$
\begin{aligned}
\mathrm{i} & =1, \cdots, \mathrm{I} \text { consumers; } \\
\mathrm{j}, \mathrm{k} & =1, \cdots, \mathrm{N} \text { brands; } \\
\mathrm{r} & =1, \cdots, \mathrm{R} \text { latent categories or clusters; } \\
\delta_{\mathrm{ijk}}= & \left\{\begin{array}{l}
1 \text { if consumer } \mathrm{i} \text { places brands } \mathrm{j} \text { and } \mathrm{k} \text { in the same pile, } \\
0 \text { else; }
\end{array}\right. \\
\mathrm{s}_{\mathrm{ijk}}= & \sum_{\mathrm{r}=1}^{\mathrm{R}} \mathrm{W}_{\mathrm{ir}} \mathbf{P}_{\mathrm{jr}} \mathrm{P}_{\mathrm{kr}} \\
= & \text { the predicted similarity (Carroll and Arabie 1983) } \\
& \text { between brand } \mathrm{j} \text { and } \mathrm{k} \text { perceived by consumer } \mathrm{i} ;
\end{aligned}
$$




$$
\begin{aligned}
\mathrm{P}_{\mathrm{jr}}= & \text { the degree of membership of brand } \mathrm{j} \text { in latent } \\
& \text { category } \mathrm{r} \text {, where } \sum_{\mathrm{r}=1}^{\mathrm{R}} \mathrm{P}_{\mathrm{jr}}=1, \forall \mathrm{j}, \text { and } 0 \leq \mathrm{P}_{\mathrm{jr}} \leq 1, \forall \mathrm{j}, \mathrm{r} ; \\
\mathrm{W}_{\mathrm{ir}}= & \text { the salience/importance weight consumer } \mathrm{i} \text { has for } \\
& \text { latent category } \mathrm{r} \text {. That is, } \mathrm{W}_{\mathrm{ir}} \text { indicates the degree } \\
& \text { to which consumer } \mathrm{i} \text { utilizes latent category } \mathrm{r} \text { in } \\
& \text { his perceptual categorization process. }
\end{aligned}
$$

Expression (1) is similar in form to the Carroll and Arabie (1983) INDCLUS model devised for the analysis of three-way, two-mode metric proximity data, where expression (1) is used (with additive constants) to model similarity judgments. However, their model is a special case of our since Carroll and Arabie (1983) restrict $P_{j r}$ to be 0 or 1 . The INDCLUS methodology is also inappropriate for the analysis of binary data. Finally, as to be shown below, INDCLUS is deterministic while our specification is stochastic in nature.

We define a latent similarity function $S_{\mathrm{ijk}}$ as:

$$
\mathrm{S}_{\mathrm{ijk}}=\mathrm{s}_{\mathrm{ijk}}+\mathrm{e}_{\mathrm{ijk}} \text {, }
$$

where:

$$
\begin{array}{ll}
\mathrm{e}_{i j k}=\operatorname{error} \sim \mathrm{N}\left(0, \sigma_{i}^{2}\right), & \\
\operatorname{Cov}\left(\mathrm{e}_{i j k}, e_{i j}^{\prime}\right)=0, & \forall \mathrm{i} \neq \mathrm{i}^{\prime}, \\
\operatorname{Cov}\left(\mathrm{e}_{\mathrm{ijk}}, \mathrm{e}_{\mathrm{irrs}}\right)=0, & \forall(\mathrm{j} \neq \mathrm{r}, \mathrm{k} \neq \mathrm{s}) .
\end{array}
$$

Now, we assume that:

$$
\mathrm{P}\left(\delta_{\mathrm{ijk}}=1\right)=\mathrm{P}\left(\mathrm{S}_{\mathrm{ijk}} \geq \mathrm{t}_{\mathrm{i}}\right),
$$

where $t_{i}$ is a consumer specific threshold parameter; here, two brands $j$ and $k$ must be perceived as "similar enough" in order to be placed in the same pile or latent category.

Then:

$$
\begin{aligned}
P\left(\delta_{i j k}=1\right) & =P\left(e_{i j k} \geq t_{i}-\sum_{r=1}^{R} W_{i r} P_{j r} P_{k r}\right) \\
& =1-\phi\left(\frac{t_{i}-\sum_{r} W_{i r} P_{j r} P_{k r}}{\sigma_{i}}\right) \\
& \text { wLOG } \\
& =1-\phi\left(t_{i}-\sum_{r} W_{i r} P_{j r} P_{k r}\right),
\end{aligned}
$$


since $\sigma_{\mathrm{i}}$ can be absorbed in the numerator. Here, $\phi$ represents the normal cdf function. Similarly,

$$
\mathrm{P}\left(\delta_{\mathrm{ijk}}=0\right)=\phi\left(\mathrm{t}_{\mathrm{i}}-\sum_{\mathrm{r}} \mathrm{W}_{\mathrm{ir}} \mathrm{P}_{\mathrm{jr}} \mathrm{P}_{\mathrm{kr}}\right)
$$

Given an independent sample of I consumers whose categorization judgments are coded into these $\delta_{\mathrm{ijk}}$ (one obtains upper/lower triangular-half binary matrices) and assuming independence over $\mathrm{i}, \mathrm{j}$, and $\mathrm{k}$ subscripts, one can form a likelihood expression:

$$
L=\prod_{i=1}^{I} \prod_{j>k}^{N} \prod(1-\phi(\cdot))^{\delta_{i j k}} \phi(\cdot)^{\left(1-\delta_{i j k}\right)},
$$

and the corresponding log-likelihood function:

$$
\operatorname{Ln} \mathrm{L}=\sum_{\mathrm{i}=1}^{1} \sum_{\mathrm{j}>\mathrm{k}}^{\mathrm{N}} \sum\left[\delta_{\mathrm{ijk}} \ln (1-\phi(\cdot))+\left(1-\delta_{\mathrm{ijk}}\right) \ln \phi(\cdot)\right] \text {, }
$$

where:

$$
\phi(\cdot)=\phi\left(t_{i}-\sum_{r} W_{i r} P_{j r} P_{k r}\right) .
$$

Thus, given the $\Delta=\left(\left(\delta_{i j k}\right)\right)$ binary data and $\mathrm{R}$, we estimate $\underset{W}{\mathrm{~W}}=\left(\left(\mathrm{W}_{\mathrm{ir}}\right)\right), \underset{\mathrm{P}}{\mathrm{P}}=$ $\left(\left(P_{j r}\right)\right)$, and $t=\left(t_{i}\right)$ to maximize $L$ or $L n L$ above. Here, $\underline{W}$ indicates how consumers weigh the derived latent categories in terms of their own categorization judgments. $\underset{\sim}{\mathrm{P}}$ indicates the membership of the $\mathrm{N}$ brands into $\mathrm{R}$ latent categories or clusters where fractional membership is allowed. And, $t$ contains threshold information as to how fine discriminations are made between brands for different consumers.

We utilize the conjugate gradient with automatic restarts procedure (Powell 1977) for parameter estimation. We impose the following constraints in the estimation: i) $W_{i r} \geq 0$, ii) $t_{i} \geq 0$, iii) $P_{j r} \geq 1$, and iv) $\sum_{r=1}^{R} P_{j r}=1$. The non-negativity constraints are implemented by substituting squared quantities for these parameters (e.g., substituting $\mathrm{W}^{2}{ }_{\mathrm{ir}}$ and $\mathrm{t}_{\mathrm{i}}^{2}$ for their respective unsquared terms in the likelihood 
expression - See Gill, Murray, and Wright 1981, pp. 268-269). The constraints on $\mathrm{P}_{\mathrm{jr}}$ in (iii) and (iv) above are operationalized by reparametrizing:

$$
\mathrm{P}_{\mathrm{jr}}=\frac{\theta_{\mathrm{jr}}^{2}}{\sum_{\mathrm{r}=1}^{\mathrm{R}} \theta_{\mathrm{jr}}^{2}},
$$

and estimating $\theta_{\mathrm{jr}}$ in order to avoid use of a constrained estimation procedure involving additional numerical complexity. An alternating conditional maximum likelihood (ACML) procedure was developed for the estimation of the model's parameters (see DeSarbo, Jedidi, and Steckel 1991).

\section{Application}

\subsection{Study description}

A small pilot study was conducted among a screened sample of potential consumers who stated they would be purchasing an automobile within the next six months ("intenders"). The purpose of this pilot study was to examine the basis of how these potential consumers perceive and categorize domestic U.S. manufactured automohiles. Initially, an exhanstive list of 78 domestic automobile "nameplates" (excluding vans and trucks) were selected for study from the 1989 Consumer Reports New Car Buying Guide. Given that many of these nameplates were similar to other nameplates produced by the same manufacturer (e.g., Ford Escort - Mercury Lynx), this list was reduced down to 28 . Table 1 presents this final list of the 28 nameplates included in this study.

Each of ten "intenders" was presented a randomized stack of 28 cards with the picture, name, and manufacturer of each automobile. The respondent was asked to sort these cards into as many or as few piles of similar automobiles as he/she thought necessary to reflect his/her perceptions.

\subsection{Traditional analyses}

As a means of comparison, six traditional clustering analyses were performed on the aggregated (over consumers) sorting frequency data: single linkage, complete linkage, average linkage, the centroid method, median linkage, and Ward's (1963) method. As one might expect, many of the resulting dendrograms were quite different with respect to shape as well as the clusters formed. In addition, Späth's (1980) KMEANS procedure, which operates on dissimilarities, was also performed and will be utilized here to illustrate the results obtained from traditional methods. Table 2 presents the summary results for $R=2, \ldots, 8$ clusters. Based 
Table 1 . U.S. automobiles for the sorting task

\begin{tabular}{ll}
\hline 1. Ford Escort & 15. Plymouth Acclaim \\
2. Ford Festiva & 16. Cadillac Seville \\
3. Geo Prizm & 17. Chrysler Fifth Ave. \\
4. Plymouth Horizon & 18. Chrysler LeBaron \\
5. Pontiac LeMans & 19. Eagle Premier \\
6. Chevrolet Corvette & 20. Ford Taurus \\
7. Ford Mustang & 21. Ford Thunderbird \\
8. Ford Probe & 22. Lincoln Continental \\
9. Plymouth Laser & 23. Oldsmobile Cutlass \\
10. Pontiac Firebird & 24. Pontiac 6000 \\
11. Buick Skyhawk & 25. Buick Le Sabre \\
12. Chevrolet Cavalier & 26. Cadillac De Ville/Fleetwood \\
13. Dodge Aries & 27. Lincoln Town Car \\
14. Ford Tempo & 28. Pontiac Bonneville \\
\hline
\end{tabular}

upon a visual inspection of the loss function, the sum-of-squared distances criterion (SSDC), one might select either $R=4$ or 6 clusters, given a leveling off of this SSDC at $R=5$ and 7 . The $R=4$ solution renders the following classification:

$\begin{aligned} \text { Luxury: } & \text { Lincoln Town Car } \\ & \text { Chrysler 5th Avenue } \\ & \text { Cadillac DeVille } \\ & \text { Cadillac SeVille } \\ & \text { Lincoln Continental } \\ \text { Sporty: } & \text { Chevy Corvette } \\ & \text { Pontiac Firebird } \\ & \text { Ford Mustang } \\ & \text { Ford Taurus } \\ & \text { Plymouth Laser } \\ & \text { Ford Probe } \\ & \text { Pontiac Bonneville } \\ & \text { Olds Cutlass } \\ & \text { Ford Thunderbird }\end{aligned}$

$\begin{aligned} \text { Mid-Size: } & \text { Eagle Premier } \\ & \text { Dodge Aries } \\ & \text { Chrysler LeBaron } \\ & \text { Plymouth Acclaim } \\ & \text { Pontiac } 6000 \\ & \text { Buick Skyhawk } \\ & \text { Chevy Cavalier } \\ & \text { Ford Tempo } \\ & \text { Buick LeSabre } \\ \text { Compact: } & \text { Geo Prism } \\ & \text { Ford Escort } \\ & \text { Plymouth Horizon } \\ & \text { Ford Festiva } \\ & \text { Pontiac Lemans }\end{aligned}$

These KMEANS results appear to describe four groups of nameplates: luxury, sporty, midsize, and compact. Most would not argue with such a classification, except perhaps with respect to several of the nameplates classified in the sporty category such as the Ford Taurus, the Pontiac Bonneville, and the Oldsmobile Cutlass which might be arguably classified in the midsize category. The corresponding six cluster solution (see Table 2) retains the luxury group intact and creates a more consistent set of five sporty nameplates. However, there is some difficulty in describing the remaining four categories. Note that these KMEANS 


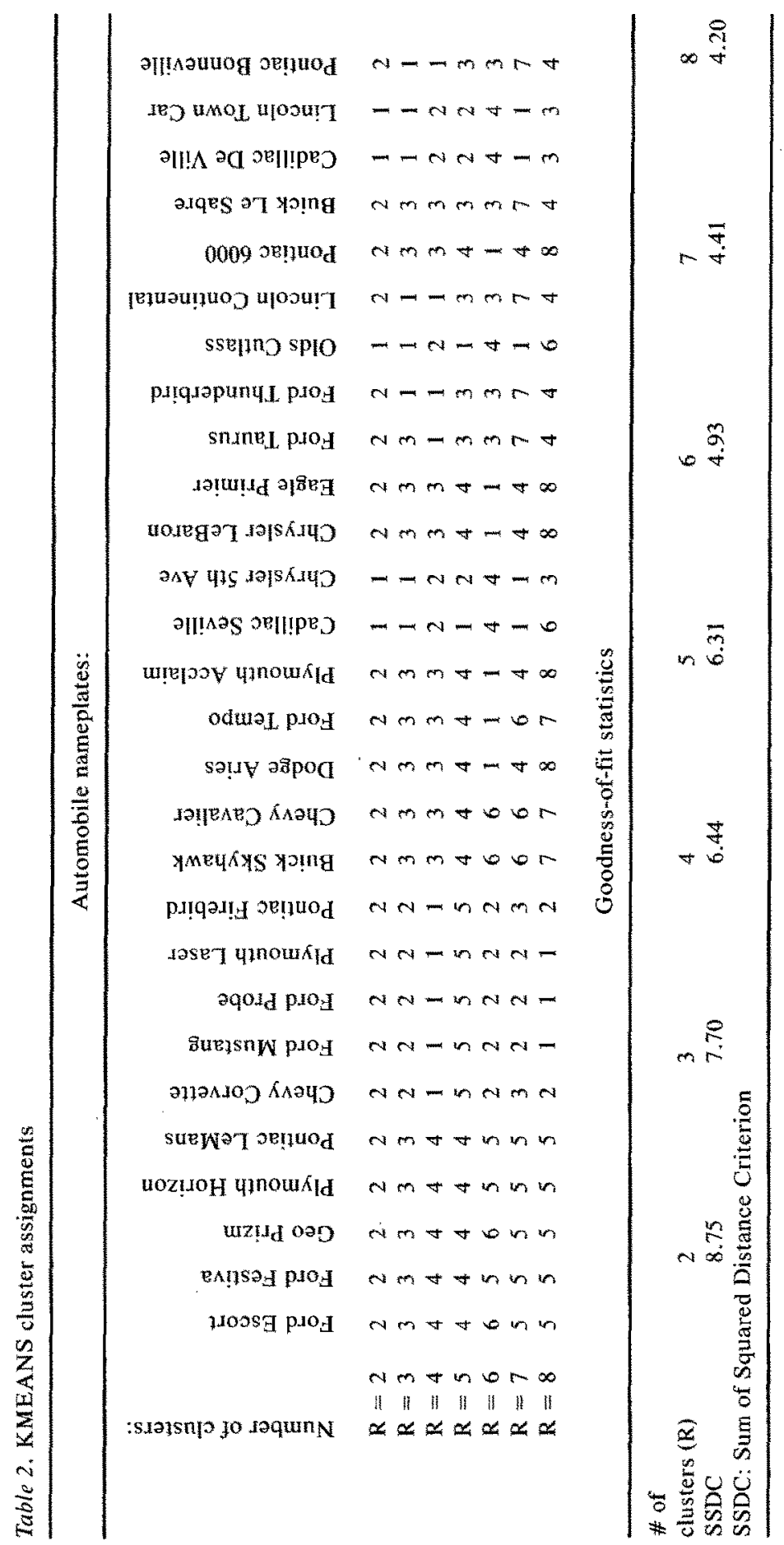


solutions were different from those obtained with the six hierarchical clustering methods.

Thus, different clustering procedures render somewhat different portrayals of the categorization process among this small set of intenders. In addition, no information concerning individual differences in categorization is provided from such methods, given the use of aggregated frequency data. Finally, all of these clustering solutions fail to capture either the prototypicality of the automobiles within clusters or potential multiple category membership of any of the nameplates.

\subsection{Analysis with the proposed methodology}

An analysis of 2-5 clusters or latent categories (as referred to here) was performed with the proposed methodology. Table 3 presents the various goodness-of-fit measures for these solutions. These various measures appear to indicate that the $R=4$ category solution appears "best" in parsimoniously describing the structure in these data.

Table 4 presents the $\underset{\sim}{\mathrm{P}}$ matrix for these 28 nameplates for the four derived categories. Upon examination of the modal values by nameplate, we see evidence of the compact, sport, midsize, and luxury categories similar to that from the KMEANS clustering. However, additional information is to be gained from a careful examination of these "probabilities of membership." An asterisk has been placed in each category (column) to denote the nameplate with the highest probability of membership, i.e., the most prototypical element. For the compact category, Ford Escort (.765) appears to be the most prototypical nameplate. This is not surprising given the traditional popularity of this particular automobile and the large amount of advertising Ford commits to this brand. For the sporty category, the Ford Mustang (.739) appears to be the most prototypical nameplate in the list. For the luxury category, the Lincoln Town Car and the Chrysler Fifth Avenue share the highest values (.743) as the most prototypical nameplates. Note an interesting finding for the midsize automobiles - the highest value in this column is substantially smaller ( .584 for Eagle Premier) than those for the previous three categories. This is consistent with recent U.S. automobile manufacturer positioning strategies which downplay the "midsize" label due to the relatively large number of competitive automobiles in this category.

Another interesting aspect of the probabilities $\left(P_{j r}\right)$ in Table 4 is that they allow for fractional membership in multiple categories (i.e., fuzzy categories). For example, the Chevy Corvette has fractional membership in both the sporty and luxury car categories. Similarly, the Buick Skyhawk is a fractional member of both the compact and midsize categories. As another example, Ford Thunderbird has almost the same degree of membership in the sporty category as in the midsize category, reflecting the previous history of the automobile as well as its mature, sporty positioning. Note, multiple category membership may also capture a lack 
Table 3. Summary goodness-of-fit statistics

\begin{tabular}{lcccccc}
\hline $\begin{array}{l}\text { Number of } \\
\text { categories (R) }\end{array}$ & D.F. & Ln L & Pbe & Phi & Match & A.I.C. \\
\hline 2 & 58 & -1824.59 & .306 & .171 & .773 & 3765.17 \\
3 & 96 & -1557.76 & .482 & .387 & .817 & 3307.52 \\
4 & 134 & -1279.96 & .629 & .557 & .860 & 2827.91 \\
5 & 172 & -1257.57 & .648 & .577 & .865 & 2859.13 \\
\hline
\end{tabular}

*Minimum A.I.C.

Table 4. The four category solution

\begin{tabular}{lllll}
\hline & Compact & Sporty & Midsize & Luxury \\
\hline 1. Ford Escort & $.765^{*}$ & .168 & .060 & .007 \\
2. Ford Festiva & .602 & .069 & .132 & .197 \\
3. Geo Prizm & .437 & .128 & .259 & .176 \\
4. Plymouth Horizon & .602 & .069 & .132 & .197 \\
5. Pontiac Lemans & .450 & .108 & .255 & .187 \\
6. Chevy Corvette & .132 & .497 & .064 & .308 \\
7. Ford Mustang & .107 & $.739^{*}$ & .121 & .034 \\
8. Ford Probe & .156 & .507 & .299 & .038 \\
9. Plymouth Laser & .161 & .473 & .326 & .040 \\
10. Pontiac Firebird & .131 & .472 & .165 & .232 \\
11. Buick Skyhawk & .333 & .110 & .489 & .067 \\
12. Chevy Cavalier & .329 & .175 & .446 & .050 \\
13. Dodge Aires & .300 & .076 & .444 & .179 \\
14. Ford Tempo & .256 & .184 & .526 & .035 \\
15. Plymouth Acclaim & .309 & .077 & .439 & .175 \\
16. Cadillac Seville & .056 & .107 & .252 & .585 \\
17. Chrysler 5th Ave. & .058 & .091 & .108 & $.743^{*}$ \\
18. Chrysler LeBaron & .153 & .133 & .489 & .225 \\
19. Eagle Premier & .133 & .235 & .584 & .049 \\
20. Ford Taurus & .072 & .346 & .546 & .037 \\
21. Ford T-Bird & .067 & .433 & .445 & .056 \\
22. Lincoln Continental & .056 & .103 & .142 & .699 \\
23. Olds Cutlass & .083 & .177 & .448 & .292 \\
24. Pontiac 6000 & .240 & .058 & .424 & .277 \\
25. Buick LeSabre & .086 & .140 & .498 & .276 \\
26. Cadillac DeVille & .056 & .095 & .248 & .608 \\
27. Lincoln Town Car & .057 & .090 & .110 & $.743^{*}$ \\
28. Pontiac Bonneville & .083 & .183 & .401 & .332 \\
\hline
\end{tabular}

*Denotes most prototypical nameplate 
Table 5. Number of sorted groups, normalized subject weights, and threshold coefficients

\begin{tabular}{lclllll}
\hline Intender & $\begin{array}{c}\text { Sorted } \\
\text { groups }\end{array}$ & Compact & Sporty & Midsize & Luxury & $\mathfrak{t}_{\mathrm{i}}$ \\
\hline 1 & 6 & .452 & .484 & .522 & .537 & 3.582 \\
2 & 3 & .775 & .431 & .290 & .360 & 3.132 \\
3 & 8 & .464 & .220 & .621 & .592 & 3.983 \\
4 & 6 & .374 & .437 & .379 & .725 & 3.393 \\
5 & 8 & .418 & .189 & .762 & .457 & 3.120 \\
6 & 5 & .530 & .453 & .589 & .409 & 4.669 \\
7 & 10 & .620 & .391 & .584 & .348 & 3.791 \\
8 & 4 & .578 & .305 & .669 & .354 & 2.425 \\
9 & 4 & .130 & .157 & .110 & .973 & 4.139 \\
10 & 8 & .536 & .558 & .430 & .465 & 2.832 \\
\hline
\end{tabular}

of familiarity, as might be the case for the relatively new Plymouth Laser and Geo Prism.

Finally, Tablc 5 presents the number of groups sorted by each intender, the normalized $\mathrm{W}$ matrix, and the $\mathrm{t}_{\mathrm{i}}$ threshold coefficients reflecting individual differences among the ten intenders. Intender 2 appears to stress the compact category in his/her categorization scheme, whereas Intender 9 appears to find the luxury category more salient. Other intenders tend to possess higher variance among their set of weights across the four categories. Rougher distinctions among the 28 nameplates appear to be made by Intenders 6 and 9 whose threshold coefficients are largest among the small sample of intenders. Thus, this methodology renders information concerning the gradient structure of a categorization scheme as well as individual differences in perception.

\section{Conclusion}

We have presented both a conceptualization of stimulus sorting and a mathematical model for the analysis of sorted stimuli based on this conceptualization. The technical details of the stochastic, individual differences clustering methodology have been provided, as well as a small illustration concerning automobile nameplate sorts. We have shown how this methodology can derive a latent categorization scheme among a set of subjects, including a quantification of the nature of individual differences - an aspect lacking in most traditional clustering techniques.

Future research should be pursued along a number of lines. Rigorous Monte Carlo testing of the proposed methodology should be undertaken to examine the 
performance of the estimation algorithm as a number of data, model, and error factors are experimentally manipulated. Algorithm performance could be measured in terms of computational effort (e.g., CPU time), parameter recovery (e.g., compare $\underset{\sim}{\mathrm{P}}$ versus $\underset{\mathbf{P}}{\hat{\mathbf{S}}}$ ), and overall goodness-of-fit (e.g., the simple matching coefficient). Generalizations of this methodology to multidimensional scaling can be made where $\mathrm{P}$ would represent a continuous space in $\mathrm{R}$ dimensions with no constraints imposed on the $\mathrm{P}_{\mathrm{jr}}$ elements. Finally, more extensive applications should be attempted utilizing the sorting data collection method and this stochastic clustering methodology.

\section{References}

Akaike, H. (1974), "A New Look at Statistical Model Identification," IEEE Transactions on Automatic Control, AC-19 716-723.

Carroll, J. D., and Arabie, P. (1983). "INDCLUS: An Individual Differen es Generalization of the ADCLUS Model and the MAPCLUS Algorithm," Psychometrika 48, 157-169.

DeSarbo, W. S., Steckel, J., and Jedidi, K. (1991). "MICROSCALE: A Stochastic Multidimen" sional Scaling Procedure for the Empirical Determination of Convex Indifference Curves of Preference/Choice Analysis," Psychometrika, forthcoming.

Gill, P. E., Murray, W., and Wright, M. H.(1981), Practical Optimization, Orlando, FL: Academic Press.

Horton, M. S., and Markman, E. M. (1980), "Developmental Differences in the Acquisition of Basic and Superordinate Categories," Child Development 51, 708-719.

Howard, J. A. (1989). Consumer Behavior in Marketing Strategy, Englewood Cliffs, NJ: Prentice Hall.

Johnson, M. D., Lehmann, D. R., and Horne, D. R. (1990). "The effects of fatigue on judgments of interproduct similarity." International Journal of Research in Marketing 7. 35-43.

Johnson, S. C. (1967). "Hierarchical Clustering Schemes," Psychometrika 32, 241-254.

Kruskal, J. B. (1964). "Multidimensional Scaling by Optimizing Goodness of Fit to a Nonmetric Hypothesis," Psychometrika 29, 1-27.

Medin, D. L., and Smith, E. E. (1984). "Concepts and Concept Formation," Annual Review of Psychology 35, 113-138.

Mervis, C. B., and Rosch, E. (1981). "Categorization of Natural Objects," Annual Review of Psy" chology 32, 89-115.

Powell, M. J. D. (1977). "Restart Procedures for the Conjugate Gradient Method," Mathematical Progrumming 12, 241-254.

Rao, V. R., and Katz, R. (1971). "Alternative Multidimensional Scaling Methods for Large Stimulus Sets," Journal of Marketing Research 8, 488-494.

Rosch, E. (175). "Cognitive Representation of Semantic Categories," Joumal of Experimental Psychology: General 104, 192-233.

Rosch, E. (1977). "Human Categorization," in W. Warren (ed.), Studies in Cross-Cultural Psychology: Volume 1, London: Academic Press, 1-49.

Sattath, S., and Tversky, A. (1977). "Additive Similarity Trees," Psychometrika 42, 319-345.

Shepard, R. N. (1962). "The Analysis of Proximities: Multidimensional Scaling with an Unknown Distance Function, I and II," Psychometrika 27, 125-140 and 219-246. 
Shepard, R. N., and Arabie, P. (1979). "Additive Clustering: Representation of Similarities as Combinations of Discrete Overlapping Properties, Psychological Review 86, 87-123.

Späth, H. (1980). Cluster Analysis Algorithms, New York, NY: Wiley \& Sons.

Ward, J. H. (1963). "Hierarchical Grouping to Optimize an Objective Function," Journal of the American Statistical Association 58, 236-244. 